PENELITIAN

\title{
Perbandingan Efek Kecepatan Injeksi 0,4 ml/dtk Dan 0,2 ml/dtk Prosedur Anestesi Spinal Terhadap Kejadian Hipotensi Pada Seksio Sesaria
}

\section{A Comparison Between The Effect Of Injection Rate Of 0,4 ml/sec And 0,2 $\mathrm{ml} / \mathrm{sec}$ In Spinal Anesthesia Procedure On Hypotension Incidence In Sectio Caesaria}

\author{
Syafri Kamsul Arif $₫ *$, Iwan Setiawan* \\ * Bagian Anestesiologi, Perawatan intensif dan Manajemen nyeri, Fakultas Kedokteran, Universitas Hasanuddin, Makassar \\ $\bowtie$ Korespondensi/ Correspondence: syafrikarif@yahoo.com
}

\begin{abstract}
Background: Spinal anesthesia is a regional anesthetic technique most commonly used in cesarean section procedures. This technique is a simple technique, also has a strong block quality even with volume and small doses and side effects are minimal when compared with general anesthesia. The effect usually appears after spinal anesthesia, among others hypotension. Incidence of hypotension after spinal anesthesia reach 30-80\% in cesarean section deliveries

Objective: To determine whether spinal anesthesia injection slower can reduce the incidence of hypotension in cesarean section without affecting the onset of anesthesia blocks.
\end{abstract}

Methods: The research used single blind randomized method with 48 samples who fulfilled the inclusion criteria. The samples were divided into two groups, fast and slow group. Spinal anesthesia was given using hyperbaric bupivacaine 0,5\% of $10 \mathrm{mg}$ and fentanyl $25 \mathrm{mcg}$. The fast group received spinal anesthesia injection with a rate 0,4 $\mathrm{mL} / \mathrm{sec}$, while the slow group received spinal anesthesia injection with a rate of 0,2 $\mathrm{mL} / \mathrm{sec}$. Hypotension incidence, onset block and the incidence of post spinal anesthesia side effects were recorded and analyzed statistically.

Results: Aanesthesia injection with a rate of $0,2 \mathrm{~mL} / \mathrm{sec}$ can reduce the incidence of hypotension after spinal anesthesia without reducing the onset and block height.

Conclusion: Spinal anesthesia with a speed of $0.2 \mathrm{~mL} /$ can reduce the incidence of hypotension after spinal anesthesia without affecting the onset and the block height.

Keywords : Spinal anesthesia, hypotension, pregnant mothers, injection rate.

\section{ABSTRAK}

Latar belakang: Anestesi spinal merupakan teknik anestesi regional yang paling sering digunakan pada prosedur seksio sesaria, selain karena teknik yang sederhana, 
juga memiliki kualitas blok yang kuat walaupun dengan volume dan dosis yang kecil, efek samping yang minimal bila dibandingkan dengan anestesi umum. Efek yang biasanya muncul pasca anestesi spinal antara lain hipotensi. Insiden hipotensi pasca anestesi spinal mencapai 30-80\% pada persalinan seksio sesaria.

Tujuan: Untuk mengetahui apakah injeksi anestesi spinal yang lebih lambat dapat mengurangi insiden hipotensi pada seksio sesaria tanpa memengaruhi onset blok anestesi.

Metode: Penelitian ini menggunakan metode acak tersamar tunggal, sampel penelitian sebanyak 48 orang yang memenuhi criteria inklusi. Sampel dipilih secara acak dan dibagi ke dalam dua kelompok. Anestesi spinal menggunakan bupivakain 0,5\% 10mg dan fentanyl 25mcg, kelompok IC dilakukan injeksi anestesi spinal dengan kecepatan 0,4 mL/ dtk, sedangkan kelompok IL dilakukan injeksi anestesi spinal dengan kecepatan 0,2 mL/ dtk. Insiden hipotensi, onset blok dan insiden efek samping pasca anestesi spinal dicatat dan dilakukan analisis statistik.

Hasil: Penelitian ini mendapatkan Injeksi anestesi dengan kecepatan 0,2 mL/dtk dapat mengurangi insiden hipotensi pasca anestesi spinal tanpa memengaruhi onset dan tinggi blok.

Kesimpulan: Anestesi spinal dengan kecepatan 0,2 $\mathrm{mL} / \mathrm{dtk}$ dapat mengurangi insiden hipotensi pasca anestesi spinal tanpa memengaruhi onset dan tinggi blok.

Kata kunci: Anestesi spinal, hipotensi, ibuhamil, kecepatan injeksi.

\section{PENDAHULUAN}

Anestesi spinal merupakan teknik anestesi regional yang paling sering digunakan pada prosedur seksio sesaria, selain karena teknik yang sederhana, juga memiliki kualitas blok yang kuat walaupun dengan volume dan dosis yang kecil, efek samping yang minimal bila dibandingkan dengan anestesi umum, walaupun memiliki efek samping yang minimal. Efek yang biasanya muncul pasca anestesi spinal antara lain hipotensi, spinal tinggi sampai dengan total spinal, hal ini dihubungkan dengan penyebaran obat di ruang subarachnoid, yang ditentukan oleh multi faktor, seperti kondisi fisik pasien itu sendiri atau karakteristik dari anestetik lokal, juga dengan teknik injeksi yang digunakan. ${ }^{1}$

Hipotensi pasca anestesi spinal (AS) merupakan insiden yang paling sering muncul, kurang lebih 15 - 33\% pada setiap injeksi AS. $^{2}$ Kasus pembedahan yang berhubungan dengan hipotensi, tertinggi ditemukan pada bagian obstetri dengan 11,8\%, bila dibandingkan dengan bedah umum 9,6\% dan hipotensi akibat trauma $4,8 \%$, insiden hipotensi maternal pada seksio sesaria akibat anestesi spinal mencapai 83,6\% 
sedangkan pada prosedur anestesi epidural $16,4 \% .^{3}$

Berbagai macam metode untuk mencegah atau mengurangi insiden hipotensi pasca anestesi spinal, telah dilakukan beberapa penelitian kurang lebih tiga dekade dengan hasil yang bervariasi. Chinacoti \& Tritrakarn (2007), mencoba menurunkan insiden hipotensi dengan cara mengurangi dosis anestesi lokal, ${ }^{4}$ Mercier \& Fischer (2013), menggunakan teknik kombinasi vasopressor dan koloading hydroxyethylstarch merupakan metode yang terbaik untuk menurunkan insiden hipotensi pasca AS. $^{2}$ Mirea \& Ungureanu(2013), kemudian menggabungkan teknik koloading Hes dan injeksi AS yang lambat menurunkan insiden hipotensi berat dan penggunaan vasopressor pada geriatri. ${ }^{5}$

Penelitian tentang kecepatan injeksi anestesi spinal telah dilakukan kurang lebih dua dekade, juga dengan hasil bervariatif. Casati dkk (1998), membuat kesimpulan bahwa teknik injeksi anestesi spinal yang sangat lambat tidak memberikan keuntungan secara klinis pada prosedur anestesi spinal unilateral. ${ }^{6}$ Anderson \& Brydon (2001), menggunakan dua kecepatan 10 detik dan 3 menit memberikan hasil yang berbeda, dimana injeksi yang lambat menggunakan bupivakain tunggal memberikan hasil onset dan pemulihan obat yang lebih cepat. $^{7}$ Singh dkk (2007), melakukan penelitian tentang perbedaan kecepatan injeksi, dengan kecepatan $>4$ detik dan $>40$ detik menggunakan bupivacaine 0,75\% ditambahkan morfin $200 \mathrm{mcg}$, didapatkan hasil bahwa injeksi AS yang cepat dengan bupivakain hiperbarik tidak mempengaruhi penyebaran obat anestesi lokal, dan tidak ada perbedaan bermakna terhadap insiden hipotensi dan mual muntah. ${ }^{8}$ Prakash dkk (2010), menggunakan kecepatan injeksi 0,38 $\mathrm{mL} / \mathrm{dtk}$ dan $0,05 \mathrm{~mL} / \mathrm{dtk}$ dan mendapat kesimpulan bahwa kecepatan injeksi AS yang berbeda pada pasien geriatri yang menjalani TUR-P tidak memiliki perbedaan dalam hal karakteristik blok. $^{9}$

Dengan adanya hasil dan efek yang bervariasi dari berbagai penelitian, penelitian ini bertujuan melihat injeksi anestesi spinal yang lebih lambat dapat mengurangi insiden hipotensi pada seksio sesaria tanpa memengaruhi onset blok anestesi.

\section{METODE}

Penelitian ini uji klinis acak dan tersamar tunggal, dilakukan dengan mengambil populasi ibu hamil usia 1840 tahun dengan IMT $18-40 \mathrm{~kg} /$ $\mathrm{m}^{2}$ kategori pasien ASA PS 1-2 yang direncanakan persalinan seksio sesaria. Dari total 90 populasi diambil 52 yang masuk dalam criteria inklusi dipilih secara counsecutive random sampling. 8 sampel di keluarkan dari penelitian, 2 karena obat anestetik local tidak adekuat, 6 sampel dikeluarkan Karena tidak sesuai kecepatan injeksi, tiap 
kelompok masing-masing 24 sampel, menggunakan anestestik local Bupivacain 0,5\% $10 \mathrm{mg}$ ditambahkan Fentanyl $25 \mathrm{mcg}$.

Sampel dibagi dalam dua kelompok, yang pertama yang mendapat perlakukan di injeksi anestesi spinal dengan kecepatan $0,4 \mathrm{~mL} / \mathrm{dtk}$ selanjutnya disebut kelompok IC. Sedangkan kelompok yang kedua mendapatkan perlakuan injeksi anestesi spinal dengan kecepatan $0,2 \mathrm{~mL} / \mathrm{dtk}$ selanjutnya disebut kelompok IL.

Pasien di persiapkan terlebih dahulu dengan premedikasi ondansentron $4 \mathrm{mg}$ dan Ranitidin 50 mg, Pada saat tiba di kamar operasi, pasien dipasang alat untuk monitor tanda vital yang akan menjalani operasi seksio sesaria, diberikan preloading dengan larutan kristaloid ringer laktat 10 - $15 \mathrm{ml} / \mathrm{kgbb}$ selama 15 menit sebelum injeksi anestesi spinal, kemudian tanda vital diukur sebelum pasien di posisikan untuk left lateral decubitus selanjutnya disebut $\mathrm{T} 0$.

Anestesi spinal dilakukan dengan menggunakan jarum spinal (Spinocan ${ }^{\circledR}$ )no.25G yang di insersi padacelah vertebra lumbal 3-4 menggunakan jarum disposible 3cc dengan pasien posisi left lateral decubitus (LLD).

Kelompok IC menerima bupivakain hiperbarik $10 \mathrm{mg}$ ditambahkan Fentanyl $25 \mu \mathrm{g}$ dengan kecepatan injeksi $0.4 \mathrm{ml} /$ detik dengan total waktu injeksi 6 detik, sedangkan kelompok IL menerima bupivakain hiperbarik $10 \quad \mathrm{mg}$ ditambahkan Fentanyl $25 \mu \mathrm{g}$ dengan kecepatan injeksi $0.2 \mathrm{ml} /$ detik dengan total waktu injeksi 12 detik, di ukur dengan menggunakan alat pencatat waktu.

Setelah injeksi, pasien diposisikan supine dengan bantal di bawah kepala dan di berikan $\mathrm{O}_{2}$ lewat nasal kanul 3 L/menit. Akhir injeksi anestetik local adalah waktu untuk mengukur ketinggian blok dinilai menggunakan tes "pinprick". Pada garis midklavikular kiri dan kanan observasi ketinggian blok dilakukan setiap menit sampai dengan didapatkan blok sensoris menggunakan tes pinprick setinggi thorakal 6 dan blok motorik dengan skala bromage 4, selanjutnya operasi dapat dimulai.

Tekanan darah sistolik, tekanan darah diastolic dan tekanan arteri rerata di ukursetiapmenitsampaidengan 15 menitpertama, setelahitusetiap lima menitsampai 35 menit atau sampai selesai operasi. TD diukur dengan metode non invasive. Insiden hipotensi dicatat apabila tekanan darah turun $20 \%$ dari T0 atau TAR $<60 \mathrm{mmHg}$, dicatat juga nilai tekanan darah terendah selama pengukuran sejak T0, bila terjadi hipotensi diberikan cairan kristaloid secara koloading disertai dengan injeksi efedrin 5-10mg setiap menit sampai tekanan darah didapatkan dalam batas normal. Efek samping lain yang muncul selama periode 
pengukuran di catat dan dilakukan analisastatistik, insiden hipotensi dan efek samping lain dianalisa dengan uji chi-square, onset blokanestesi spinal dianalisa dengan ujiindependent- $t$

\begin{abstract}
Analisa data menggunakan SPSS 22 untuk Macintosh, Karakteristik sampel, Karakteriatik hemodinamik pascaanestesi spinal dan karakteristik blok anestesi spinal di uji menggunakan ujii ndependent-t. Insiden hipotensi dan efek samping lain selama penelitian di uji menggunakan ujiChi-Square.Data ditampilkan dalam bentuk table dan narasi.
\end{abstract}

\section{HASIL}

Distribusi sampel menurut umur, gestasi, berat badan, tinggi badan, IMT, TDS T0, TDD T0 dan TAR T0 di uji normalitas dengan $1-s$ Kolmogorov-smirnov test dan didapatkan distribusi sampel normal, selanjutnya dilakukan uji perbandingan menggunakan independet t-test, hasil ditampilkan dalam tabel 1.

Dari hasil uji statistik pada karakteristik sampel didapatkan tidak ada perbedaan bermakna antara kedua kelompok, dengan ini dapat disimpulkan bahwa distribusi data homogen antara kedua kelompok.

Karakteristik hemodinamik dinilai satu menit setelah injeksi anestesi spinal, dihitung setiap menit selama 15 menit pertama, kemudian setiap 5 menit sampai menit ke 35 , hasil perbandingan hemodinamik antara kedua kelompok ditampilkan dalam tabel 2.

Tekanan darah dan tekanan arteri rerata terendah rata-rata antara kedua kelompok dinilai sejak T1 kemudian dibandingkan antara kedua kelompok. Pada TDS didapatkan hasil pada kelompok IC 79,13 \pm 15,04 dan kelompok IL 94,67 $\pm 12,15$ dengan nilai $P=0,000$, didapatkan perbedaan bermakna antara kedua kelompok. Penilaian TDD pada kedua kelompok didapatkan hasil pada kelompok IC 45,08 \pm 7,35 dan kelompok IL 50,67+ 8,50 dengan nilai $P=0,019$, didapatkan perbedaan bermakna antara kedua kelompok. Penilaian TAR pada kedua kelompok didapatkan hasil pada kelompok IC 58,83 \pm 11,30 dan kelompok IL 66,63 \pm 10,19 dengan nilai $P=0,016$, ditemukan perbedaan bermakna antara kedua kelompok. Waktu rata-rata terjadinya hipotensi pertama dihitung satu menit sejak anestesi spinal, terjadinya insiden hipotensi awal pada kedua kelompok dibandingkan, pada kelompok IC 3,95 \pm 2,09 dan pada kelompok IL 3,89 \pm 1,97 dengan nilai $P=0,939$, tidak didapatkan perbedaan bermakna dalam hal menit terjadinya hipotensi pertama antara kedua kelompok.

Total dan nilai rata-rata penggunaan efedrin pada kedua kelompok didapatkan pada kelompok IC $430 \mathrm{mg}(17,92+10,72)$, sedangkan pada kelompok IL $135 \mathrm{mg}$ (5,63 + $8,76)$ dengan nilai $p=0,000$. Didapatkan 
perbedaan bermakna kebutuhan efedrin rata-rata pada IC dan IL, dapat disimpulkan bahwa injeksi anestesi spinal yang lebih lambat dapat mengurangi kebutuhan efedrin selama pembedahan.

Insiden hipotensi didapatkan pada kedua kelompok, pada kelompok IC didapatkan insiden hipotensi 21 dari 24 sampel, sedangkan pada kelompok IL didapatkan 9 dari 24 sampel, dan berdasarkan hasil uji statistik chi square antara kedua kelompok didapatkan hasil kelompok IC 87,5\%, kelompok IL $37,5 \%$ dengan $P=0,001$ didapatkan hasil yang berbeda bermakna antara kedua kelompok, hasil ditampilkan dalam tabel 3 .

Efek samping yang muncul antara kedua kelompok didapatkan delapan kejadian efek samping pada kedua kelompok, pada kelompok IC didapatkan 25\% kejadian efek samping, sedangkan pada kelompok IL 8,3\% kejadian efek samping, berdasarkan jumlah insiden efek samping yang muncul antara kedua kelompok tidak ditemukan perbedaan bermakna dengan nilai $P=0.245$. Berdasarkan insiden mual muntah pada kedua kelompok tidak ditemukan perbedaan bermakna antara kedua kelompok. Efek samping depresi nafas pada kedua kelompok juga tidak ditemukan perbedaan bermakna dengan nilai $p=0,609$.

Karakteristik blok anestesi spinal ditampilkan dalam tabel 4 untuk membandingkan onset obat anestesi spinal antara kedua kelompok, onset obat dinilai dengan tes pinprick untuk menilai blok sensoris dengan target setinggi thorakal 6 dan skala bromage empat untuk menilai blok motorik, kemudian onset blok motorik dan blok sensorik dinilai terpisah untuk melihat perbedaan onset efek dari perbedaan kecepatan injeksi.

Tidak ada perbedaan bermakna antara kedua kelompok dalam hal onset tercapainya blok anestesi spinal, baik dalam hal blok sensoris dan blok motoris, onset blok antara kedua kelompok dapat dicapai pada menit 3-4 setelah injeksi anestesi spinal. Berdasarkan hasil yang didapatkan, dapat disimpulkan bahwa kecepatan injeksi anestesi spinal tidak berpengaruh terhadap onset blok anestesi spinal.

\section{PEMBAHASAN}

Penelitian ini memperlihatkan bahwa kecepatan injeksi yang lebih lambat dapat mengurangi kejadian hipotensi pasca anestesi spinal, tanpa memengaruhi onset dan tinggi blok anestesi spinal.Hasil yang bervariasi antara beberapa penelitian dapat disebabkan karena perbedaan metode penelitian, kosentrasi anestetik lokal yang digunakan, posisi pasien saat injeksi, lokasi insersi anestesi spinal, perbedaan kecepatan pada tiap uji klinis dan juga karakteristik populasi. Kecepatan injeksi bervariasi mulai dari $0,05 \mathrm{~mL} / \mathrm{dtk}$ sampai dengan $>4$ detik, 
beberapa peneliti menggunakan syringe pump untuk akurasi ketepatan injeksi, berbeda dengan penelitian ini kecepatan injeksi di ukur menggunakan stopwatch dengan posisi injeksi LLD.

Penelitian ini dilakukan pada wanita hamil, dimana wanita hamil dihubungkan dengan blok sensoris yang lebih tinggi setelah injeksi dengan bupivakain hiperbarik, faktor yang dapat mempengaruhi antara lain, kurvatur tulang belakang, peningkatan tekanan intra abdomen, melebarnya vena - vena di ruang epidural, dan berkurangnya ruang dalam daerah subarachnoid menjadi lebih sempit, juga dapat dihubungkan dengan peningkatan sensitifitas neuronal akibat meningkatnya hormon progesteron.

$$
\text { Singh et al(2007), }
$$

menyimpulkan bahwa kecepatan injeksi yang berbeda tetap memberikan efek hipotensi dengan efek samping mual dan muntah $^{8}$, berbeda dengan penelitian ini, kecepatan injeksi yang lebih lambat dapat mengurangi kejadian hipotensi, hal ini dapat disebabkan karena perbedaan konsentrasi anestetik lokal yang digunakan pada penelitian Singh menggunakan bupivakain hiperbarik $0,75 \%$ sedangkan pada penelitian ini menggunakan bupivakain hiperbarik $0,5 \%$, dimana konsentrasi anestetik lokal merupakan faktor major yang memengaruhi sebaran di ruang subarachnoid.
Kang dkk (2012), melakukan uji

klinis mengenai kecepatan injeksi anestesi spinal antara dua kelompok menggunakan bupivakain 0,5\% $9 \mathrm{mg}$ dengan fentanyl 10 mcg dengan kecepatan $0,1 \mathrm{~mL} / \mathrm{dtk}$ dan $0,02 \mathrm{~mL} / \mathrm{dtk}$ pada wanita hamil, di dapatkan kecepatan injeksi yang lebih lambat tidak berpengaruh terhadap onset dan level blok sensoris, dan juga tidak mengurangi insiden hipotensi, tapi menunda onset terjadinya hipotensi ${ }^{10}$, hal ini berbeda dengan hasil penelitian ini dimana insiden hipotensi dapat berkurang dengan injeksi lebih lambat, hal ini mungkin dikarenakan metode yang berbeda dalam hal kriteria objektif, dimana kriteria hipotensi dari Kang ditentukan apabila TAR $<100$ mmHg sedangkan pada penelitian ini kriteria hipotensi apabila TAR < $60 \mathrm{mmHg}$.

Casati dkk (1998), memperlihatkan onset blok yang dicapai setelah injeksi hingga mencapai thorakal enam membutuhkan waktu lima sampai tujuh menit ${ }^{6}$, sejalan dengan penelitian ini dalam hal tercapainya onset tiga sampai empat menit, hal ini sejalan dengan beberapa penelitian sebelumnya bahwa, kecepatan injeksi anestesi spinal lambat ataupun cepat tidak berpengaruh terhadap sebaran anestetik lokal di ruang subarachnoid.

$$
\text { Hanazaki dkk }
$$
melakukan penelitian tentang kecepatan injeksi dan efek samping yang muncul 
pasca anestesi spinal, memperlihatkan efek injeksi yang cepat dapat mencapai onset blok kurang dari 5 menit, namun efek yang tidak nyaman dapat muncul seperti sesak nafas ${ }^{11}$, sejalan dengan penelitian ini bahwa insiden efek samping lebih banyak ditemukan pada kelompok injeksi yang lebih cepat, walaupun secara statistik tidak berbeda bermakna, hal ini dapat disebabkan karena efek injeksi yang cepat dapat meningkatan turbulensi diruang subarachnoid sehingga meningkatkan sebaran obat ke arah chepalad, apalagi jika pada ibu hamil yang mengalami perubahan fisiologis yang berpengaruh terhadap sebaran anestetik lokal di ruang subarachnoid, seperti tekanan intraabdomen yang meningkat karena adanya janin, ruang intratekal yang lebih sempit dan sensitifitas saraf yang meningkat sehingga resiko terjadinya hipotensi lebih tinggi.

\section{SIMPULAN}

Berdasarkan hasil penelitian ini menjawab hipotesa awal, yaitu, injeksi anestesi spinal yang lebih lambat dapat mengurangi insiden hipotensi tanpa mempengaruhi onset dan tinggi blok. Faktor yang dapat menjadi perancu hasil dari penelitian ini berupa, adanya resiko perdarahan yang muncul di 5-10 menit awal operasi yang dapat menyebabkan terjadinya hipotensi sehingga mengaburkan hasil pengukuran.

Tabel 1. Karakteristik sampel

\begin{tabular}{|c|c|c|c|}
\hline \multirow[t]{2}{*}{ Variabel (Mean_SD) } & \multicolumn{2}{|c|}{ Kelompok } & \multirow[t]{2}{*}{$P$} \\
\hline & $\mathrm{IC}(\mathrm{n}=24)$ & $\mathrm{IL}(\mathrm{n}=24)$ & \\
\hline Umur (tahun) & $28,38 \pm 5,74$ & $30,88 \pm 7,44$ & 0,199 \\
\hline Gestasi (minggu) & $39,08 \pm 1,44$ & $38,88 \pm 1,85$ & 0,665 \\
\hline Beratbadan (kg) & $60,83 \pm 8,39$ & $62,88 \pm 10,26$ & 0,454 \\
\hline TinggiBadan $(\mathrm{cm})$ & $155,75 \pm 5,45$ & $156,79 \pm 4,42$ & 0,471 \\
\hline IMT $(\mathrm{kg} / \mathrm{m} 2)$ & $25,01 \pm 2,51$ & $25,48 \pm 3,24$ & 0,581 \\
\hline TDS T0 (mmHg) & $124,67 \pm 7,26$ & $123,75 \pm 8,26$ & 0,685 \\
\hline TDD T0 (mmHg) & $80,04 \pm 7,14$ & $79,04 \pm 7,27$ & 0,633 \\
\hline TAR T0 (mmHg) & $94,87 \pm 6,05$ & $93,92 \pm 6,75$ & 0,607 \\
\hline
\end{tabular}

Data ditampilkan dalam rata-rata \pm SD, uji normalitas menggunakan Uji Kolmogorov-Smirnov test, uji distribusi sampel antara kedua kelompok menggunakan independent t-test, berbeda bermakna jika $\mathrm{P}<0,05$ 
Tabel 2. Karakteristik hemodinamik setelah injeksi anestesi spinal

\begin{tabular}{cccc}
\hline Variabel (Mean+SD) & \multicolumn{2}{c}{ Kelompok } & \multirow{2}{*}{} \\
\cline { 2 - 3 } & $\mathrm{IC}(\mathrm{n}=24)$ & $\mathrm{IL}(\mathrm{n}=24)$ & \\
\hline Nilai SBP terendah $(\mathrm{mmHg})$ & $79,13 \pm 15,04$ & $94,67 \pm 12,15$ & $0,000^{*}$ \\
\hline DBP terendah $(\mathrm{mmHg})$ & $45,08 \pm 7,35$ & $50,67 \pm 8,50$ & $0,019^{*}$ \\
\hline TAR terendah (mmHg) & $58,83 \pm 11,30$ & $66,63 \pm 10,19$ & $0,016^{*}$ \\
\hline $\begin{array}{c}\text { Waktuygdibutuhkanuntuk episode } \\
\text { hipotensipertama (mnt) }\end{array}$ & $3,95 \pm 2,09$ & $3,89 \pm 1,97$ & 0,939 \\
\hline $\begin{array}{c}\text { Total dan Rata - rata } \\
\text { penggunaanefedrin (mg) }\end{array}$ & $430(17,92 \pm 10,72)$ & $135(5,63 \pm 8,76)$ & $0,000^{*}$ \\
\hline
\end{tabular}

Data ditampilkan dalam rata-rata $+\mathrm{SD}$. Uji independent-t, berbeda bermakna bila $\mathrm{P}<0.05 *=$ ditemukan perbedaan bermakna antara kedua kelompok dalam hal rata-rata +SD TDS, TDD, TAR, Penggunaan efedrin rata-rata. Tidak ada perbedaan bermakna antara kedua kelompok menit terjadinya hipotensi, dan insiden mual muntah dan depresi nafas.

Tabel 3. Insiden hipotensi dan efek samping lain

\begin{tabular}{cccc}
\hline Variabel & Kelompok & P \\
\cline { 2 - 3 } & IC (n=24) & IL $(\mathrm{n}=24)$ & $0,001^{*}$ \\
\hline Insidenhipotensi (n) & $21(87,5 \%)$ & $9(37,5 \%)$ & 0,245 \\
\hline Efeksamping (n) & $6(25 \%)$ & $2(8,3 \%)$ & 0,609 \\
\hline Nausea (n) & $3(12,5 \%)$ & $1(4,1 \%)$ & 0,609 \\
\hline Depresinafas(n) & $3(12,5 \%)$ & $1(4,1 \%)$ & \\
\hline
\end{tabular}

Data ditampilkan dalam angka dan persentasi, menggunakan uji chi-square, bermakna bila $p=<0,05$. *berbeda bermakna dalam hal insiden hipotensi antara kedua kelompok

Tabel 4. Karakteristik blok anestesi spinal

\begin{tabular}{|c|c|c|c|}
\hline \multirow[t]{2}{*}{ Variabel $($ Mean \pm SD) } & \multicolumn{2}{|c|}{ Kelompok } & \multirow[t]{2}{*}{$P$} \\
\hline & IC & IL & \\
\hline $\begin{array}{l}\text { Waktu yang dibutuhkanuntukmencapai } \\
\text { onset (mnt) }\end{array}$ & $2,96 \pm 1,73$ & $3,62 \pm 1,66$ & 0,180 \\
\hline $\begin{array}{l}\text { waktuygdibutuhkanbloksensorismen- } \\
\text { capaithorakal } 6(\mathrm{mnt})\end{array}$ & $2,75 \pm 1,80$ & $3,62 \pm 1,66$ & 0,087 \\
\hline $\begin{array}{l}\text { Waktuyg di butuhkanblokmotorikmen- } \\
\text { capaiskalabromage } 4 \text { (mnt) }\end{array}$ & $2,21 \pm 1,32$ & $2,71 \pm 1,20$ & 0,176 \\
\hline
\end{tabular}

Data ditampilkan dalam rata-rata $+\mathrm{SD}$, waktu yang dibutuhkan untuk mencapai onset keseluruhan, waktu yang dibutuhkan untuk mencapai thorakal 6 dan skala bromage 4 di uji dengan independent $t$-test, bermakna bila $\mathrm{p}=<0,05$ 


\section{DAFTAR PUSTAKA}

1. Kee N. Prevention of maternal hypotension after regional anaesthesia for caesarean section. Current opinion in anaesthesiology, 2010. 23(3):304-9.

2. Mercier, FJ \& Fischer, C. Maternal hypotension during spinal anesthesia. Minerva Anesth, 2013. 79(1):62 - 73.

3. Metzger, A.,et al. Maternal hypotension during elective cesarean section and short term neonatal outcome, 2010. Am J Obstet Gynecol. 202:56.

4. Chinocati, T \& Tritrakarn, T. Prospective study of hypotension and bradicardia during spinal anesthesia with bupivacaine : Incidence with risk factor. J Med Assoc Thai, 2007. 90(3):492-501

5. Mirea, LE \&Ungureanu, R. Effect of injection speed and colloid loading on hypotension associated with spinal anesthesia for orthopedic surgery in elderly patient. Euro J Anaesth, 2013. 30:133-4

6. Casati A, Fanelli G, Cappelleri G, et al. Does speed of intratheca injection affect the distribution of $0.5 \%$ hyperbaric bupivacaine? $\mathrm{Br}$ J Anaesth1998;81: 355-7
7. Anderson, L\& Brydon,C. Rate of injection trough whitacre needles affects distribution of spinal anesthesia, Brit J Anaesth, 2001. 86 (2):245-8.

8. Singh SI, Morley-Forster PK, Shamsah M, Butler R. Influence of injection rate of hyperbaric bupivacaine on spinal block in parturients: a randomizedtrial. Can J Anesth, 2007. 54(4):290-5.

9. Prakash, S \& Barthiga, V. The effect of injection speed on the spinal block characteristic of hyperbaric bupivacaine $0,5 \%$ in elderly. J Anesth., 2010. 24(6);7781

10. Kang, YI, Bang EC, Shin DW, Kweon DE, Kim SY, Lee HS, dkk. Effect of injection speed of local anesthetic on hypotension during spinal anesthesia for cesarean section. Ewha Med J, 2012. 35(2):83 - 8 .

11. Hanazaki, M.,et al. (1997). Effect of injection speed on sensoris blockade in spinal anesthesia with $0,5 \%$ hyperbaric tetracaine. Masui J, 1997. 46(6):777 - 82. 